\title{
Amynthas carnosus (Goto \& Hatai, 1899) redescribed on its neotype (Oligochaeta: Megadrilacea: Megascolecidae)
}

\author{
Robert J. Blakemore* \\ National Institute of Biological Resources, Incheon 404-170, Korea \\ *Correspondent: rob.blakemore@gmail.com
}

\begin{abstract}
Japanese/Korean Amynthas carnosus (Goto \& Hatai, 1899) is redescribed from a newly designated Neotype (Tokyo NSMT An435). An annotated synonymy is presented that nominally includes: kyamikia Kobayashi, 1934, monstrifera Kobayashi, 1936, sangyeoli, youngtai, kimhaeiensis, sinsiensis and baemsagolensis - all Korean names by Hong \& James, 2001, and Taiwanese monsoonus James et al., 2005. However, Chinese A. pingi (Stephenson 1925) (syn. fornicata Gates, 1935) is maintained separately, at least for the present, until its comprehensive review, possibly extending to DNA barcode differentiation.
\end{abstract}

Keywords: Asian taxonomic housekeeping, invasive earthworm synonyms, pheretimoid

\section{INTRODUCTION}

Morphological classification of earthworms depends on correct counting of segments. Much confusion has surrounded Japanese Amynthas carnosus (Goto \& Hatai, 1899) due to its poor original account and subsequent mis -descriptions. The main problem was that the spermathecal pores were initially described in 5/6/7/8 but the spermathecae were stated to be in 7,8 and 9 , suggesting they exited in 6/7/8/9; yet one set was missed and exits were actually in $5 / 6 / 7 / 8 / 9$. Related to this error, the genital markings were miscounted in 7 and 8 while being in 8 and 9, and dorsal pores were said to be in 13/14 rather than correctly in 12/13 (The spermathecal diverticula bulb was also seemingly broken off in Goto \& Hatai's fig. 5). These facts were determined by Kobayashi (1936a) and by Ohfuchi (1937) who both worked on Japanese/Korean fauna with tacit support from Dr Shinkishi Hatai, the original author. However, Gates $(1939,365 p$.) rejected this data for no valid reason. Next Sims \& Eason (1972) and then Easton (1981), who was mainly concerned with Japanese fauna, apparently missed these references and retained carnosa, albeit with a question mark, under $A$. gracilis (Kinberg, 1867) having spermathecal pores in 5/6/7/ 8. Unaware of the Korean reviews but realizing that Easton (1981) was mistaken, Blakemore (2003) formally restored Japanese A. carnosus while adding some provisional synonyms that had accrued subsequently. These were further refined in revisions of the Japanese/Korean and Taiwanese faunas by Blakemore (2004; 2007; 2008). Seemingly confusion yet reigns: In particular, Shen et al.'s (2005, 95p. fig. 1) account of A. carnosus from Taiwan seems to be based on some other taxonomic entity, as flagged by Blakemore et al. (2006, 228p.).

As a first step reviewing regional fauna before publishing "new" names, it is essential both to read the literature and to attempt to determine the fate of type specimens from earliest reports onwards. Extensive searches of Japanese collections eventually uncovered a few of Goto \& Hatai's syntypes (see Blakemore \& Ueshima, 2011), but types of $A$. carnosus are not known. This paper presents a species redescription based on a formal Japanese Neotype of $A$. carnosus in order to objectively clarify its taxonomic status compliant with current ICZN (1999) recommendations.

\section{Materials ANd Methods}

The Neotype was contained within an historical 1920s collection from Saito Ho-on Kai Museum, Sendai (where Dr Shinkishi Hatai worked as director) that was transferred in 2006 to the National Museum of Nature \& Science (NMNS) in Tokyo, and where the cataloguing of its $>1,200$ earthworm specimens has been compiled and kindly made available by curator Dr Toshiaki Kuramochi. The taxonomic determination herein follows the style, systematics, methodology and conventions in Blakemore (2000; 2002; 2010c). Small tissue samples were taken from non-essential posterior segments as per Blakemore et al. (2010a) for DNA analyses and (CO1) barcoding, but results thus far have been unsuccessful on this older material. 


\section{TAxonomic Results}

Annelida Lamarck, 1802: Oligochaeta Grube, 1850: Megadrilacea Benham, 1890: Megascolecidae Rosa, 1891 sensu Blakemore, 2000.

Amynthas Kinberg, 1867.

\section{Amynthas carnosus (Goto \& Hatai, 1899)}

Perichaeta carnosa Goto \& Hatai, 1899: 15, 24, figs. 4, 5. [From Tokyo. Described on two specimens - see Note below. Types not known despite extensive searches by current author for $10 \mathrm{yrs}$ in Japan (cf. Blakemore \& Ueshima, 2011)].

Amyntas hawayanus (part.): Beddard, 1900: 645; Gates, 1932: 433.

Pheretima carnosa: Michaelsen, 1900: 260; Chen, 1936: 274 (when describing $P$. pingi chungkingensis, that possibly merits elevation to species level, remarked that $P$. pingi Stephenson, 1925 was probably a synonym of carnosa); Kobayashi, 1936a: 115, tab. 1, text figs. 1-3 (syns. pingi, kyamikia), 1938: 161; Ohfuchi, 1937b: 56, fig. 9, Pl. 1, 4; Kobayashi, 1938: 161; ?Chen, 1959: 9, fig. 9 (part. syn. pingi); Gates, 1972: 149; Ishizuka, 2001: 75, fig. 32; Nakamura, 1999: 27 (name misspelt "canosa").

Pheretima kyamikia Kobayashi, 1934: 1, figs. 1-3. [From North Korea. Types unknown, but a non-type specimen from "(Tetsugen) Kogen-do" sent by S. Kobayashi was added in synonymy of $P$. pingi by Gates (1939: 465). Kobayashi's (1934: fig. 1) is the same as Chen's (1959: fig. 9i variation) for carnosa (syn. pingi). Named for Korean vernacular "kyamiki" meaning "dog bait" or "useless as fishbait"].

Pheretima monstrifera Kobayashi, 1936b: 168, fig. 11. [From Seoul and other localities. Agreeing with Kobayashi (1936a: tab. 1, and text-figs. 1XII \& 2I)]. Syn. nov.

Amynthas carnosus: Sims \& Easton, 1972: 235 [lapsus in A. hawayanus (= gracilis) group]; Blakemore, 2003: 13 +43 addendum (syns. ?distichus, kyamikia, ?youngtai, sangyeoli); 2004; 2007; 2008 (syns. ?pingi, kyamikia, ?youngtai, sanyeoli); Shen et al., 2003: 484 (syn. sangyeoli); [?non Shen et al., 2005: 95; nec. Tsai et al., 2009: 38; nec. Chang et al., 2009: 32, fig. 12].

Pheretima diffringens (part.): Gates, 1972: 149.

Amynthas gracilis (part.): Easton, 1981: 50.

Amynthas youngtai Hong \& James, 2001b: 269, fig. 1AC. [From Jeju (=Quelpart), Korea - the same place whence Kobayashi (1938: 161) had already recorded $A$. carnosus - apparently from some other locations too. Types put in Korean Institute of Biodiversity Research (KIBIO), Jeonbuk National University, but details are unclear. Uncertainty due to segmental miscounts between authors' fig. 1 and somewhat confused descrip- tion but, nevertheless, it mostly agrees, at least with Kobayashi (1936a: tab. 1 and text-figs. 1VII \& 2X)].

Amynthas kimhaeiensis Hong \& James, 2001b: 270, fig. 2A-C. [From Korea. Type in Korea. Description of spermathecal pores and figures do not quite correspond, yet apparently agreeing at least with Kobayashi (1936a: text-figs. 1XI or XII \& 2II)]. Syn. nov.

Amynthas sangyeoli Hong \& James, 2001b: 271, fig. 3AC. [Korean types, materials and type-material locations seem rather confused. Markings near male and spermathecal pores, and the spermatheca exactly the same as Goto \& Hatai's corrected figures from 102 years earlier, as well as those of Kobayashi (1934; 1936a), Ohfuchi (1937), Chen (1936; 1959), etc. dating from $\sim 69$ years ago].

Amynthas sinsiensis Hong \& James, 2001b: 272, fig. 4AC. [From Korea. Types? Agreeing both with A. monstriferus and Kobayashi (1936a: text-figs. 1I or II or IV \& 2I)]. Syn. nov.

Amynthas baemsagolensis Hong \& James, 2001b: 274, fig. 5A-C. [From Korea. Types? Agreeing both with $A$. sinsiensis and Kobayashi (1936a: text-figs. 1I \& 2I)]. Syn. nov.

?Amynthas monsoonus James et al. 2005: 1012. [From Taiwan. Cf. regarded as a junior synonym of $A$. tungpuensis Tsai et al., 1999 by Tsai et al. (2009). Probable instant synonymy of all nine "new" species was already suggested to the authors in manuscript review, prior to publication in a referee's report sent to journal editor 8.I.2004 (as online in Blakemore, 2010b and as attached in Appendix), but this advice was manifestly ignored. Their named specimen agrees somewhat with Kobayashi's (1936a: text-figs. 1XVII \& 2I) and Chen's (1959: fig. 9 variations)].

Note. Goto \& Hatai (1899: 15) said: "Two specimens presenting a difference of some importance in the genital papillae around the male pores. We shall base our description on the larger specimen, which is also provided with more genital papillae." They then proceeded to poorly describe both specimens that they said were otherwise identical and thereby commenced introduction of 100+ years of confusion and uncertainty. These two original syntypes are not traceable in any known Japanese collection (as already noted).

Material inspected. Tokyo, NMST An435, formol preserved Neotype (Fig. 1) labeled "Ph carnosa (Goto and Hatai) [Kanji for Sendai-city] 1923-1925" part of Saito Ho-on Kai Museum Collection, possibly inspected and labeled by Dr Hatai who was original author, or one of his students e.g. Shinryo Ohfuchi. The date precludes it being a syntype. One mature specimen with tip of tail missing, previously undissected and here figured and dissected with small tissue samples taken to attempt DNA 


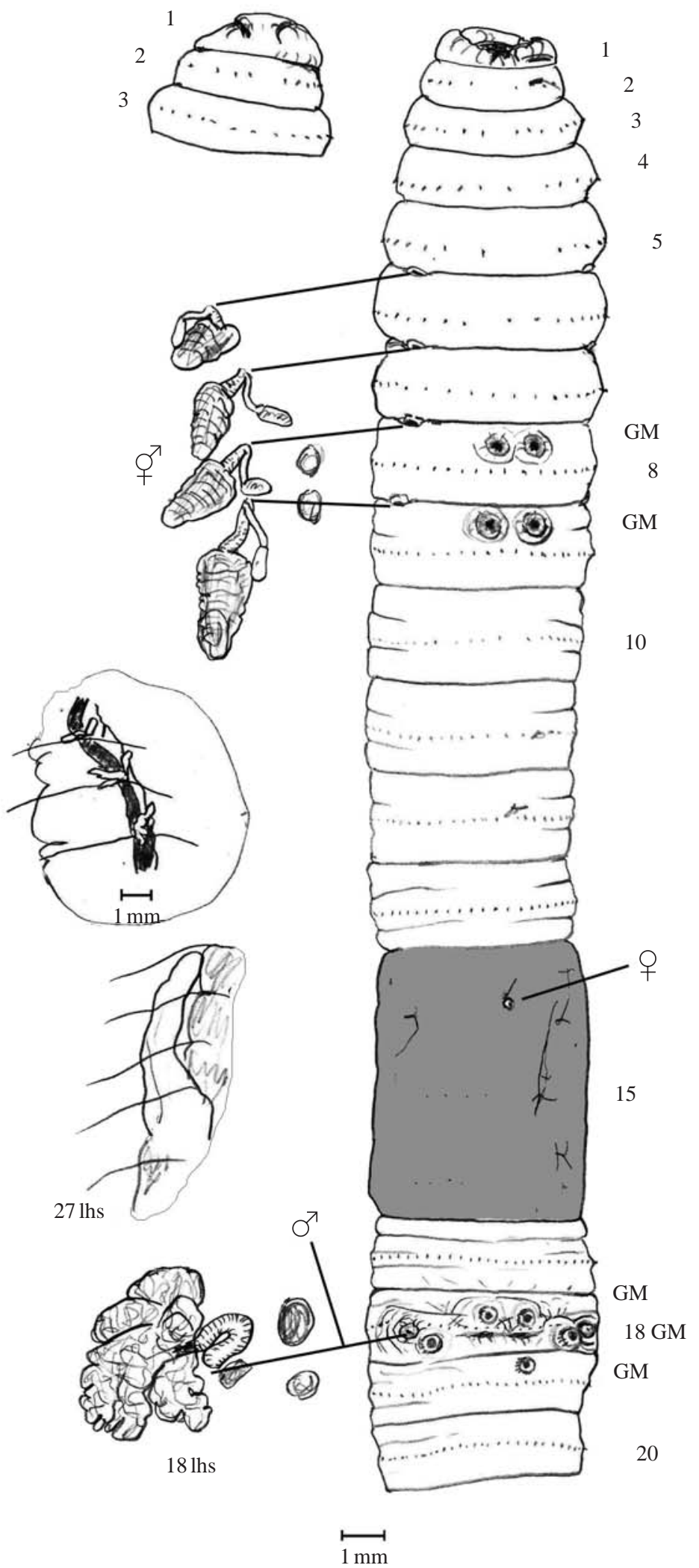

Fig. 1. Amynthas carnosus (Goto \& Hatai, 1899) NSMT An435 Neotype showing prostomium, ventral view of body with spermathecae and prostates in situ (GM=Genital Marking with internal glands); also septal glands on dorsal blood vessel and intestinal caecum (Ihs=left side). 
barcoding.

Diagnosis. Size $110-247 \mathrm{~mm}$. Spermathecal pores in 5/6/ $7 / 8 / 9$ or rarely in 6/7/8/9 (Goto \& Hatai confused them in 5/6/7/8). Dorsal pores typically from 12/13. Genital markings typically closely paired mid-ventral and presetal in 8-9 and often also in 18-19 with other pairs just posterior (and sometimes anteriorly) median to the male pores; some variation apparently acceptable, including complete absence of markings. Intestinal caeca simple.

Distribution. Japan (Goto \& Hatai, 1899; Kobayashi, 1936a; Ohfuchi, 1937; Easton, 1981 - from Kyushu to Tohoku and Hokkaido from reports he quotes by Kobayashi, 1936, 1941 and Yamaguchi, 1962); Korea and Jeju-do (=Quelpart) Island (Kobayashi, 1936a; 1936b; 1937; 1938); China (Chen, 1959); claimed from Jiangsu, Zhejiang, Anhui, Shandong, Hong Kong, Sichuan, and Beijing [from Chinese Agricultural Academy of Science website: www.agrionline.net.cn/zhuanti/index.htm (2005), whence Pheretima carnosa (sic) is dubiously described with either three or four pairs of spermathecae in 5/6/7/8, $8 / 9$, possibly including $P$. pingi subspecies]; Vietnam (unconfirmed as $P$. pingi). Relatively recently A. carnosus was (?mis-)described from Taiwan by Shen et al. (2005); this requires confirmation as noted by Blakemore $e t$ al. (2006: 228).

Description (Neotype compared to the original descriptions and synonymy above, excluding typical $\mathrm{A}$. pingi characteristics). Body length $180+$ mm (cf. 143-153 by Goto \& Hatai or 110-247 by Kobayashi, 1936a), segments $111+$ (cf. $106-126$ by Goto \& Hatai or $110-179$ by Kobayashi). Dark brown dorsum with darker clitellum. First dorsal pore 12/13 (cf. 13/14 Goto \& Hatai lapsus, or 11/ $12 / 13$ in some other accounts). Setae 24-69. Spermathecal pores wide in 5/6/7/8/9 (initially confused by Goto \& Hatai as 5/6/7/8). Genital markings closely paired presetally in 8 and 9 (7 and 8 according to Goto \& Hatai, lapsus - Fig. 2), in 18 and often in 19; other markings just anterioventral to superficial male pores in 18 postsetally (neotype in agreement except that 19rhs presetal is unilateral - Fig. 1); in Goto \& Hatai's second specimen and $50 \%$ of Kobayashi's material both these mid-ventral pairs in 18 and 19 were absent and sometimes no markings were near male pores either, while a few other specimens lacked markings entirely or had extra markings in 18 . Considerable variation was permitted in both preclitellar and postclitellar marking locations by Kobayashi (1936a) - Fig. 3. Sessile glands correspond to the markings internally. No accessory pore glands noted, neither near to spermathecal nor to male pores (cf. Shen et al., 2005). Internally the pharyngeal mass extends to 4 and tufted meroic nephridia are in 5 and 6. Septa 8/9/10 are aborted or $8 / 9$ sometimes retained and displaced by gizzard (Kobayashi, 1936a: 116); 10/11/12 and sometimes 12/13 are strong; thereafter membranous. Spermathecae in 6-9, the
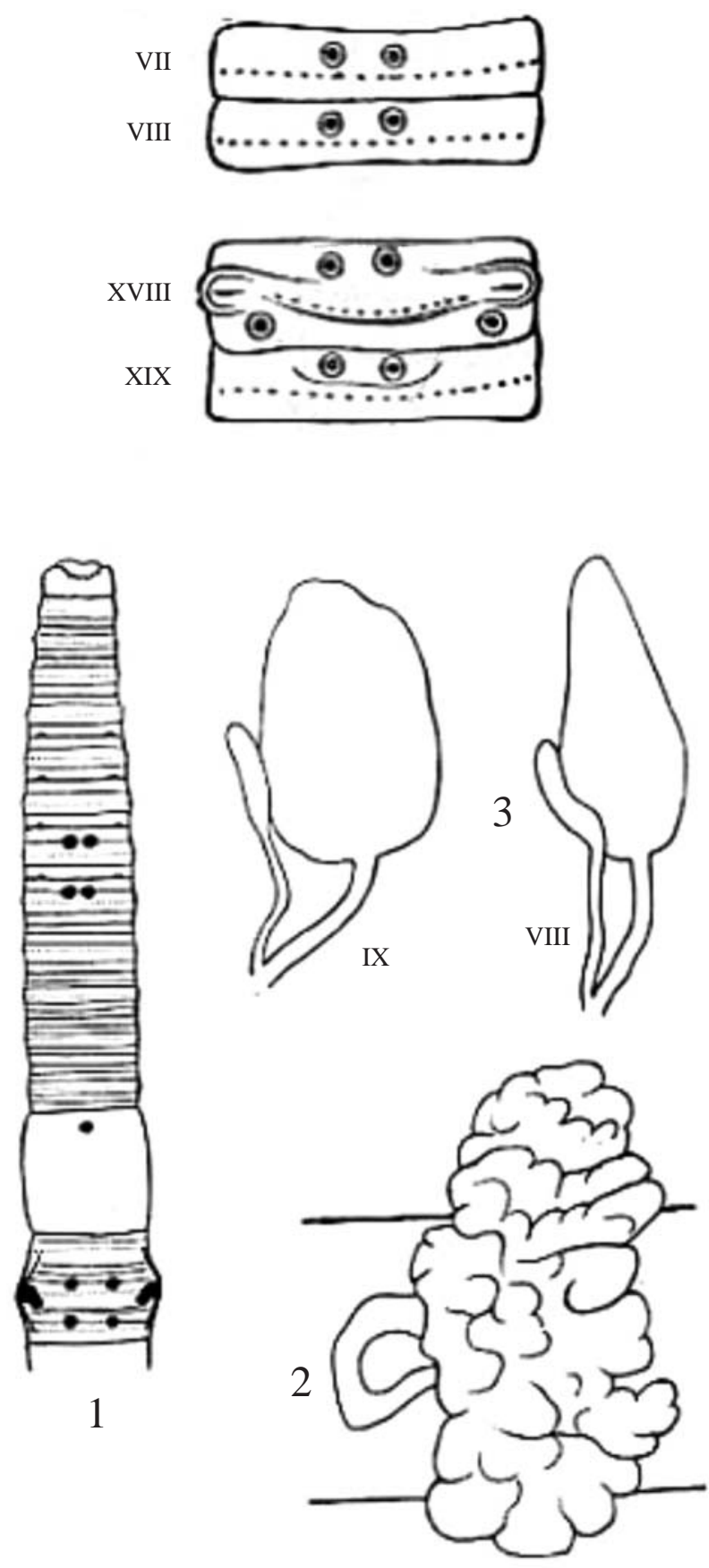

Fig. 2. Amynthas carnosus: upper Goto \& Hatai's original fig. 4; lower Ph. kyamikia Kobayashi, 1934, figs. 1-3 (as exactly similar in syns. youngtai and sangyeoli).

first pair often smaller (and sometimes absent) the last two pairs after septum 7/8; with diverticula about half the length of duct plus ampulla. Last hearts in 13. From ca. 15/16 distinct paired septal glands on dorsal blood vessel occur (Fig. 1). Seminal vesicles with dorsal appendages in 11 and 12. Ovaries in 13 with vestigial ovisacs on posterior of 13/14. Intestine origin in 15 with simple caeca 
Type number

Number of specimens

Type number

Number of specimens

Type number

Number of specimens

Number of specimens

Type number

Number of specimens

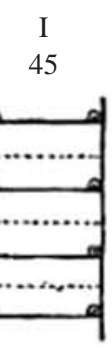

II

III

47
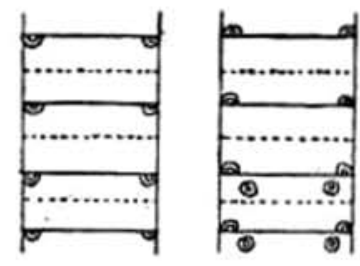

IV

V

VI

32
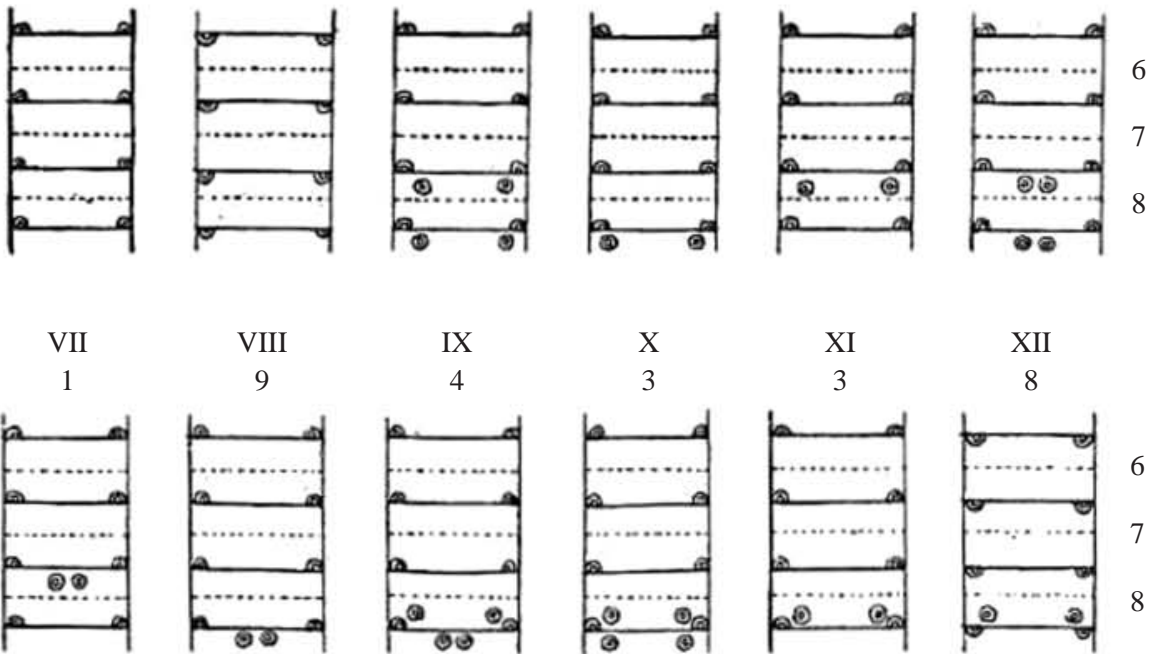

VIII

9

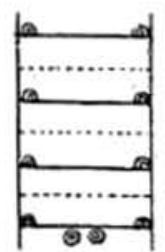

IX

$\mathrm{X}$

XI

XII
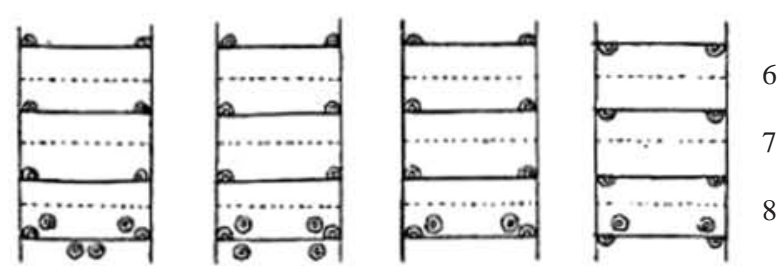
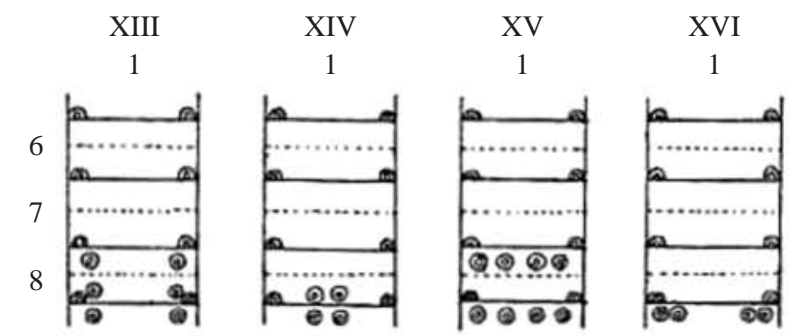

XVII

Text-fig. 1. Seventeen types of the preclitellar genital papillae.
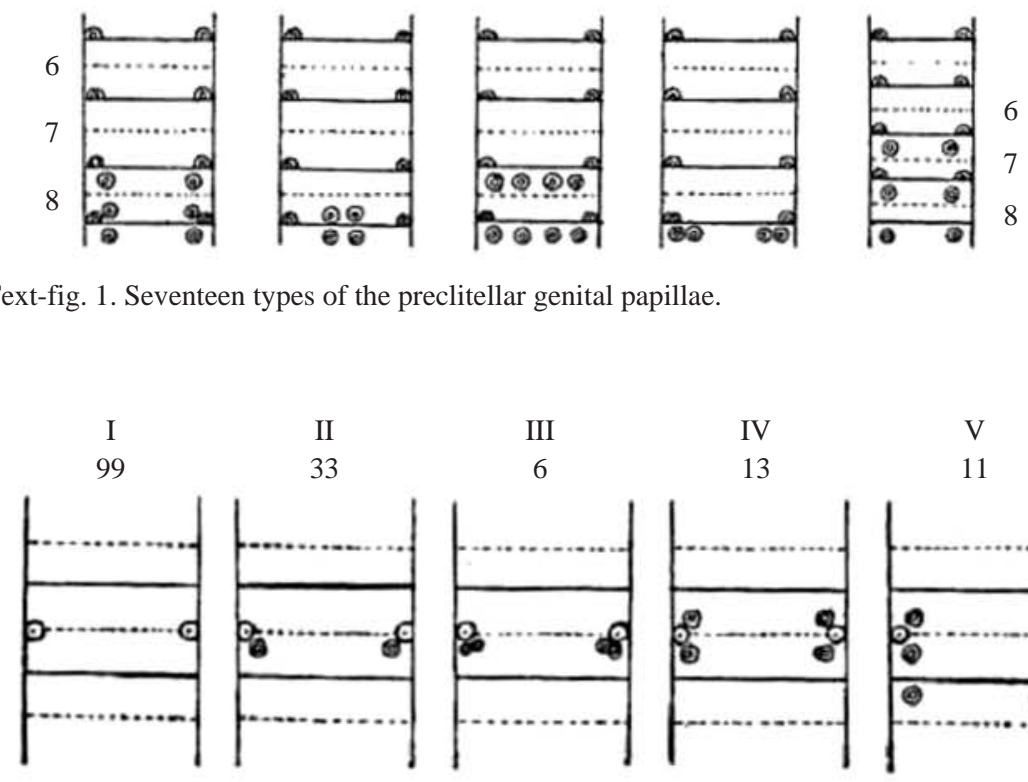

III

IV

$\mathrm{V}$
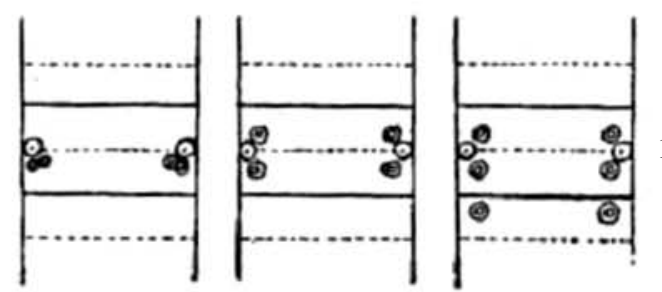

18
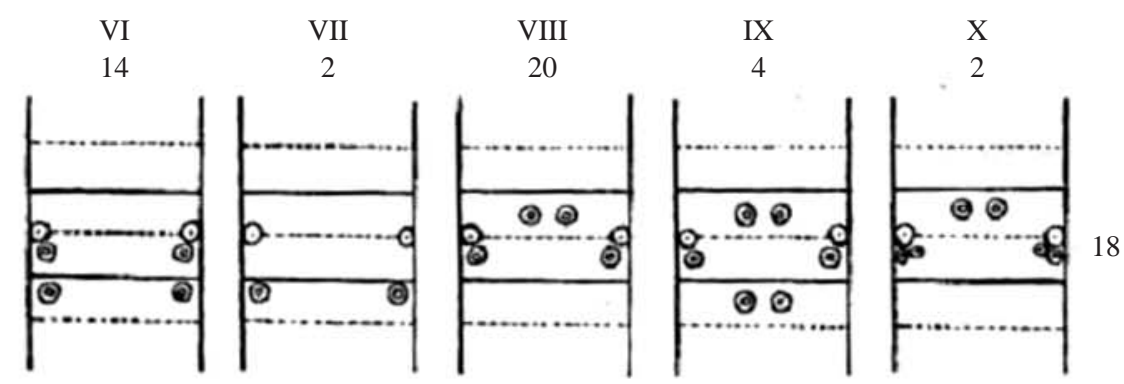

Text-fig. 2. Ten types of the postclitellar genital papillae.

Fig. 3. Variation in genital markings and spermathecal pores from Kobayashi (1936: text-figs. 1-2) showing permissible variations as determined by his detailed study. 
from 27 extnding forward to 24 or 23. Gut contains yellow soil in Neotype, i.e., low organic content suggesting a geophageous diet.

\section{Discussion}

Regarding distributions, the exact Tokyo type-locality is not known; however, the authors worked from the FirstHigh-School which was in Ueno (if they collected there) that later became integrated as the Komaba campus of The University of Tokyo (Todai). Searches found no further old or new material, neither in the collections (cf. Blakemore \& Ueshima, 2011), in the grounds (Todai campus and Ueno Park) which surely will have changed greatly since 1899, nor in wider surveys around Tokyo. Kobayashi (1936a: 136) described two specimens from Morioka that were sent to him from the Saito Ho-on Kai collection (with the tacit agreement of S. Hatai) and another 204 samples from Korea. He thought this species was introduced to Japan from either China or Korea, or from both of them, although it might equally be endemic to both Japan and Korea (where it has garnered many synonyms) or to China. If it truly occurs in Taiwan, it might be an introduction there. Alternatively, as Chen (1936: 275 ) first suggested when describing $P$. pingi chungkingensis, were Amynthas pingi (Stephenson, 1925) synonymous with $A$. carnosus, then this taxon might be more prevalent in China and its centre of origin more obscure. Gates (1943) described a single specimen of Pheretima pingi from 3,000-5,000 ft at Kuatun, Fukien China. However, genital markings of his specimen were nearly coincident with the spermathecal and male pores plus another two pairs just median to the male pores, one presetal and one postsetal, the latter in contact with, but distinct from, the male porophore; thus it is questionably whether it is either A. pingi or A. carnosus.

Synonyms are debatable too. Inclusion of $A$. pingi requires caution as it is, on average, a larger worm with several other differences that presently exclude it from $A$. carnosus proper, pending further study based on British Museum types (Blakemore in prep., cf. Gates, 1939). Kobayashi (1936a) studied 204 Korean specimens of $A$. carnosus allowing up to eight markings in some of 7,8-9 and six or fewer in 18-19 that he thought encompassed the variations found in A. pingi. Several of his specimens lacked markings entirely: 51 (of 204) from the preclitellar region, and 99 (from 204) from the male pore region (see Fig. 3). Two of Kobayashi's Korean carnosa were sexthecal with spermathcal pores in 6/7/8/9 only.

Kobayashi's (1936b) subsequent octothecal species, Pheretima monstrifera (=Amynthas monstriferus) was said to be easily distinguished by its larger size $(235 \mathrm{~mm})$ and genital papillae in 8 . Yet he had already described body length of 111-247 mm and shown eight of his 204 specimens of carnosa to have markings in segment 8 (Kobayashi, 1936a: fig. 1XII), corresponding to those shown for monstrifera by Kobayashi (1936b: fig. 11.2). Since the characteristics of monstrifera are enveloped it now enters the ambit of $A$. carnosus synonymy based on acceptance of Kobayashi's (1936a) account.

Hong \& James (2001: 271, fig. 3) started to describe their A. sangyeoli directly above fig. 2 of an allegedly different other species but they appeared to count the segments correctly in their fig. 3 (cf. their fig. 1) as they described a "sp. nov." in exact agreement with both A. carnosus (Goto \& Hatai, 1899) and with Kobayashi (1934)'s $P$. kyamikia from Korea that also did not differ from Kobayashi's and Ohfuchi's redecriptions of A. carnosus (with spermathecae correctly located in 5/6/7/8/9 as in their own Amynthas youngtai-despite its figured segments miscounted). It thus appears that Hong \& James have ignored previous Japanese or Korean papers crucial to Korean earthworm taxonomic study. Rather than being "sp. nov." their A. youngtai, A. kimhaeiensis, A. sangyeoli, A. sinsiensis and A. baemsagolensis are all similar and mainly mutually compared, yet comply with variations allowed by Kobayashi (1936a) in his redescription of $A$. carnosus from Korea. The latter two synonymous names appear to be mere redescriptions of Kobayashi (1936b)'s Korean "Amynthas monstrifera" ( $\mathrm{sic}=A$. monstriferus) and thus join it as new combinations in A. carnosus.

The A. sangyeoli synonym was independently determined by Shen et al. (2003: 484, tab. 2) nearly 10 years ago. Unfortunately, web searched still hit student guides, and field reports from Korea retaining the sangyeoli and other junior synonyms [e.g. http://data.gbif.org/species/ search.htm?c[0].s $=1 \&$ pageno $=2 \& c[0] .0=465 \& c[0] . p=0$ and http://geoworm.ccbb.re.kr/renew/index.php] and are yet quoted as if valid in Agricultural research papers e.g., Na et al. (2010). This should be immediately corrected.

Apart from its smaller size and absence of markings, Korean A. sangumburi Hong \& Kim, 2002 is similar but it is currently incertae sedis as its segments are also miscounted in these authors' fig. 4; despite this it seems conspecific with Amynthas toriii (Ohfuchi, 1941). Moreover, Amynthas monsoonus James et al. 2005: 1012 from Taiwan is perhaps in the ambit of A. carnosus as it has the same classical markings in 7-9, but its spermathecae are in 6/7/8/9, as permitted some of Kobayashi (1936a)'s specimens, leading him, and the current revision, to accept this as a rare interspecific variation. A. monsoonus is, nevertheless, most often regarded as a junior synonym of A. tungpuensis Tsai et al., 1999, e.g. by Tsai et al. (2006; 2009) (cf. Appendix). Further basic work is required to determine these affinities.

Shen et al.'s (2005: 95, fig. 1) account of Amynthas carnosus from Taiwan seems to be based on some other 
taxon as the genital makings and spermathecae differ considerably from those in the current and past accounts. For instance, markings are small and numerous around the spermathecal pores, and the spermathecal diverticula are long and dilated, looking more paprika-like. Thus identification is suspect. Chang et al. (2009: 64, fig. 28) also showed markings (e.g. in 19) that differ from 'typical' $A$. carnosus but resemble Shen et al.'s (2005) version which, as noted above, is questionable. Possibly confusion is with Kobayashi (1936a: 129)'s "Spermathecal papillae" - by which he means merely small pads - surrounding the spermathecal pores and not necessarily separate gland pores which are not typically found near the spermathecal nor male pores in $A$. carnosus proper. If they were present, Kobayashi or Ohfuchi would presumably have noted this. Nevertheless, Chen (1959: fig. 9) shows a composite gland on a spermathecal pore of his "carnosa" (syn. pingi). Similarly, Gates' (1939, 1943) concept of A. ping $i$ seems somewhat removed from the present idea of A. carnosus so its identity and therefore its combination in prior $A$. carnosus, requires consideration. Both listings are provisionally excluded from A. carnosus and A. pingi is retained separately.

There is residual possibility that the genital marking variation in A. carnosus allowed for by Kobayashi in his detailed and most thorough account is excessive, rather representing a congeries of morphs, if not separate species, varying somewhat from the typical form described herein. However, this has yet to be proven by rigorous study and, meanwhile, numerous new names have been needlessly added. The prior taxon Amynthas divergens (Michaelsen, 1892) as well as other components of the A. corticis (Kinberg, 1867) species-complex have been mutually confused with A. carnosus during their long and chequered histories. Comparable parts of the A. corticis and A. exiguus (Gates, 1930) spp-complexes are provided for by Blakemore (2002, 2006, 2008, 2010c) with the proviso that DNA analyses may ultimately decide boundaries.

That mtDNA COI barcoding was so far unsuccessful for the Neotype is disappointing, but not critical as many other historical types are preserved in formaldehyde and we can hope that technology will soon allow extraction of their DNA. In the meantime, the fixing of the morphology of its name-bearing type will now facilitate routine testing from morphologically compliant specimens whether from Taiwan, Japan, Korea or elsewhere.

Article 75 of ICZN (1999) concerns designations of Neotypes with the express purpose of clarifying the taxonomic status (or type-locality) when objective identity is in doubt, as is clearly the case with A. carnosus (Goto \& Hatai, 1899). Other qualifying conditions are met in relevant statements expressed in the body of this paper above. One lesser concern is the type-locality which in this case was Tokyo; and while it is not ideal that the current specimen was labelled as from "Sendai", this probably has little bearing when this species distribution is known to extend from Hokkaido to Kyushu and Korea. Moreover, it is felt that the opportunity to designate a specimen that was most likely identified as the nominal taxon by its original author (Dr Hatai) is an overriding consideration within the spirit and brief of the ICZN Article 75 guidelines.

\section{REFERENCES}

Blakemore, R.J. 2000. Tasmanian Earthworms. CD-ROM Monograph with Review of World Families. 'VermEcology', PO BOX 414 Kippax 2615. Canberra, December, 2000, pp. 800 including 222 figures. ISBN 0-646-410881.

Blakemore, R.J. 2002. Cosmopolitan Earthworms - an EcoTaxonomic Guide to the Peregrine Species of the World. VermEcology, PO BOX 414 Kippax, ACT 2615, Australia, pp. 506 plus 80 figs.

Blakemore, R.J. 2003. Japanese Earthworms (Annelida: Oligochaeta): a review and checklist of species. Organisms, Diversity and Evolution 3(3):241-244 [Available from: 2003-11 http://www.senckenberg.de/odes/03-11. htm].

Blakemore, R.J. 2004. Checklist of Japanese Earthworms updated from Easton (1981). In: A.G. Moreno \& S. Borges (eds.), Avances en taxonomia de lombrices de tierra/Advances in earthworm taxonomy (Annelida: Oligochaeta). Editorial Complutense, Universidad Complutense, Madrid, Spain, pp. 155-162.

Blakemore, R.J. 2007. Japanese Earthworms. In: M. Ito \& N. Kaneko (eds.), A Series of Searchable Texts on Earthworm Biodiversity, Ecology and Systematics from Various Regions of the World. CD-ROM, Yokohama National University, Japan [Available from: http://bio-eco.eis.ynu. ac.jp/eng /database/earthworm/, accessed January 2012].

Blakemore, R.J. 2008. Korean earthworm species-updated checklist. In: N. Kaneko \& M.T. Ito (eds.), A Series of Searchable Texts on Earthworm Biodiversity, Ecology and Systematics from Various Regions of the World-Supplemental [Available from: http://www.annelida.net/ earthworm/, accessed January 2012].

Blakemore, R.J. 2010a. Unravelling some Kinki worms (Annelida: Oligochaeta: Megadrili: Megascolecidae) Part II. Opuscula Zoologica 42(2):191-206 [Available from: http: //opuscula.elte.hu/PDF/Tomus41_2/3_\%20Blakemore_ Kiniki2.pdf].

Blakemore, R.J. 2010b. Unravelling some Kinki worms supplement: [Available from: http://opuscula.elte.hu/Tomus41 _2/Blakemore_App2.pdf].

Blakemore, R.J. 2010c. Cosmopolitan Earthworms - an EcoTaxonomic Guide to the Peregrine Species of the World. 
( $4^{\text {th }}$ Edn.). VermEcology So (i)lutions, Yokohama, Japan, pp. $\sim 850+\sim 350$ Figs. \& Internet links.

Blakemore, R.J. and R. Ueshima. 2011. Catalogue of Annelida: Oligochaeta in University of Tokyo Zoology Museum (ZMUT). In: R. Ushima (ed.), Catalogue of Invertebrate Collection Deposited in the Department of Zoology, the University Museum, the University of Tokyo (3), Phylum Annelida(Class Polychaeta, Oligochaeta, and Hirudinida). Material Reports, No. 90, 59-83 [Available from: http:// umdb.um.u-tokyo. ac.jp/DDoubutu/invertebrate_en/index. html].

Blakemore, R.J., C.-H. Chang, S.-C. Chuang, M.T. Ito, S. James and J.-H. Chen. 2006. Biodiversity of Earthworms in Taiwan: a species checklist with the confirmation and new records of the exotic lumbricids Eisenia fetida and Eiseniella tetraedra. Taiwania 51(3):226-236 [Available from: http://tai2. ntu.edu.tw/udth/bin/taiwania.exe/dl?id= 507 or http://tai2. ntu.edu.tw/taiwania/pdf/tai.2006.51.3. 226.pdf or http://www.press.ntu.edu.tw/ejournal/Files/ taiwan/200609/10.pdf].

Blakemore, R.J., E. Kupriyanova and M.J. Grygier. 2010. Neotypification of Drawida hattamimizu Hatai, 1930, (Oligochaeta: Megadrili: Moniligastridae) and the first COI sequence from an earthworm type. ZooKey 41:1-29 [Available from: http://pensoftonline.net/zookeys/index. php/journal/article /view/374/401].

Chang, C.-H., H.-P. Shen and J.-H. Chen. 2009. Earthworm fauna of Taiwan. National University Press, Taipei, 167p.

Chen, Y. 1936. On the terrestrial Oligochaeta from Szechuan II with the notes on Gates' types. Contribibutions of Biological Lababoratory of Science Society of China. Zoology 11:269-306.

Chen, Y. 1959. Chinese Animal Atlas. Annelida. Science Press, Beijing [In Chinese].

Easton, E.G. 1981. Japanese earthworms: a synopsis of the Megadrile species. Bulletin of the British Museum (Natural History) Zoology 40:33-65.

Gates, G.E. 1939. On some species of Chinese earthworms with special reference to specimens collected in Szechuan by Dr. D.C. Graham. Proceedings of the United States National Museum 85:405-507 [Available from: si-dppr. si.edu/dspace/bitstream/10088/16290/USNMP-85_3040 _1939. pdf].

Gates, G.E. 1943. On some American and Oriental earthworms. Ohio Journal of Science 43:87-116.

Gates, G.E. 1972. Burmese Earthworms, an introduction to the systematics and biology of Megadrile oligochaetes with special reference to South-East Asia. Transactions of the American Philosophical Society 62(7):1-326 [Available from: http://www.jstor.org/stable/1006214 in 2011].

Goto, S. and S. Hatai. 1899. New or imperfectly known species of earthworms. No. 2. Annotations Zoologicae Japonensis 3(1):13-24.

Hong, Y. and S.W. James. 2001. Five new earthworms of the genus Amynthas Kinberg, 1867 (Megascolecidae) with four pairs of spermathecae. Zoolological Studies 40(4): 269-275.

Hong, Y. and T.-H. Kim. 2002. Four new Earthworms of the genus Amynthas (Oligochaeta: Megascolecidae) from Korea. Korean Journal of Biological Science 6:195-199.

ICZN. 1999. International Code of Zoological Nomenclature ( $4^{\text {th }}$ edition). International Trust for Zoological Nomenclature, c/o Natural History Museum, London. pp. 306. [Available from: http://www.iczn.org/iczn/index.jsp].

Ishizuka, K. 2001. Taxonomic study of the genus Pheretima s. lat (Oligochaeta, Megascolecidae) from Japan. Bulletin of Seikei University 33(3):1-125.

James, S.W., H.-T. Shih and H.-W. Chang. 2005. Seven new species of Amynthas (Clitellata: Megascolecidae) and new earthworm records from Taiwan. Journal of Natural History 39(14):1007-1028.

Kinberg, J.G.H. 1867. Annulata nova. Öfversigt af Kongl. Vetenskaps-akademiens forhandlingar, Stockholm 23:97103, 356-357 [Available from: http://www.mediafire.com /file/4zqngvzztjw/Kinberg1867a.pdf].

Kobayashi, S. 1934. Three new Korean earthworms belonging to the genus Pheretima, together with the wider range of the distribution of Pheretima hilgendorfi (Michaelsen). Journal of Chosen Natural History Society 19:1-11.

Kobayashi, S. 1936a. Distribution and some external characteristics of Pheretima (Ph.) carnosa (Goto et Hatai) from Korea. Science Report of the Tohoku Imperial University 11(1):115-138.

Kobayashi, S. 1936b. Earthworms from Koryo, Korea. Science Report of the Tohoku Imperial University 11(1):139184.

Kobayashi, S. 1937. Preliminary survey of the earthworms of Quelpart Island. Science Report of the Tohoku Imperial University (B) 11(3):333-351.

Kobayashi, S. 1938. Earthworms of Korea I. Science Report of the Tohoku Imperial University 13(2):89-170.

Na, Y.E., H.S. Bang, S.I. Kwon, M.H. Kim and Y.-J. Ahn. 2010. Hazardous effects of eight years of application of four organic waste materials on earthworm numbers and biomass in field Lysimeters. Archives of Environmental Contamination and Toxicology 60:99-106 [Available from: http://www. springerlink.com/content/p415175637 03w800/].

Nakamura, Y. 1999. Checklist of Earthworms of Pheretima Genus Group (Megascolecidae: Oligochaeta) of the World. Edaphologia 64:1-78.

Ohfuchi, S. 1937. On the species possessing four pairs of spermathecae in the genus Pheretima, together with the variability of some external and internal characteristics. Saito Ho-On Kai Museum Research Bulletin 12:31-136.

Shen, H.-P., C.-F. Tsai and S.-C. Tsai. 2003. Six new earthworms of the genus Amynthas (Oligochaeta: Megascolecidae) from Central Taiwan. Zoolological Studies 42(4): 
479-490 [Available from: https://zoolstud.sinica.edu.tw/ Journals/42.4/279.pdf].

Shen, H.-P., S.-C. Tsai, C.-F. Tsai and J.-H. Chen. 2005. Occurrence of the Earthworm Amynthas carnosus (Goto and Hatai, 1899) in the Northern Taiwan. Endemic Species Research 7(1):95-100 [Available from: https://tesri. coa.gov.tw/files/tesri_protect/124/070108.pdf].

Sims, R.W. and E.G. Easton. 1972. A numerical revision of the earthworm genus Pheretima auct. (Megascolecidae: Oligochaeta) with the recognition of new genera and an appendix on the earthworms collected by the Royal Society North Borneo Expedition. Biological Journal of the
Linnaean Society, London 4:1-169.

Tsai, C.-F., H.-P. Shen, S.-C. Tsai and H.-L. Hsih. 2006. A checklist of Oligochaetes from Taiwan and Its Adjacent Islands [Available from: https://gra103.aca.ntu.edu.tw/ gdoc/D93B41001a.pdf/, accessed January 2012].

Tsai, C.-F., H.-P. Shen, S.-C. Tsai, K.-J. Lin, H.-L. Hsieh and S.-P. Yo. 2009. A checklist of oligochaetes (Annelida) from Taiwan and adjacent islands. Zootaxa 2133:33-48.

Submitted: January 18, 2012, Accepted: February 9, 2012 